\title{
Panel on Competition Policy in Card-Based Payment Systems: Commentary
}

\author{
HENRY ERGAS* \\ Vice President, CRA International
}

\begin{abstract}
The following is a transcription of my discussion of the papers (published in this issue) that were presented in the Panel on Competition Policy in Card-Based Payment Systems session of the Antitrust Activity in Card-Based Payment Systems: Causes and Consequences conference.
\end{abstract}

I've been given 15 minutes to comment on three very different papers that each would merit at least twice that time. So faced with a plainly impossible task, I've chosen to reflect in a far more general way on what we can draw from these papers and others about an important theme of this conference, which is the choice of policy instrument.

In particular, to the extent to which there are concerns about the functioning of card-based payment systems, should policy makers rely on the general instruments of competition policy or is some more targeted form of regulation appropriate?

The papers in this session help inform this question in two important ways: first, they provide many useful insights about the concerns that arise with respect to card-based payment systems. Second, together with the other papers at this conference, they highlight the extent to which the issues involved are complex and controversial, both in terms of the underlying theory and perhaps even more so in terms of the empirical evidence.

Despite this complexity and the generally unsettled nature of the debate, it does seem to me that there are some important points of agreement. First, there are strong arguments, from an economic efficiency perspective, for collectively set interchange fees in open card systems. Second, the socially efficient level of these fees would take account both of costs and of demand elasticities on the two sides of the market.

Third, actual interchange fees undoubtedly differ from those that would be set by an omniscient social planner. Whether they are systematically too high, however, is controversial and, at best, unproven. Fourth, if interchange fees are set too high, then no-surcharge rules can make the resulting distortions greater than they would otherwise be. But removing those rules may impose costs of its own; in particular, no-surcharge rules may be useful in preventing free riding by merchants and may also prevent some potentially harmful price discrimination.

Fifth, like no-surcharge rules, rules that require merchants to accept all cards issued by a system may make setting too high interchange fees more attractive than it would otherwise be.

\footnotetext{
* Mailing address: Level 1, 29 Jardine Street, Canberra ACT 2604, Australia, 61-2-6232-6522, E-mail: hergas@crai.com.au
} 
But, again, as with no-surcharge rules, and with even greater force, these honor-all-card rules can promote efficiency, including by reducing consumers' transactions costs.

Taken as a whole, these points certainly open the possibility of market failure. But it is by no means clear that markets are, in fact, failing in this area. Or, if they are, are failing to a material degree. Indeed, one might think that the spectacular worldwide popularity of card-based payment systems with consumers speaks to substantial welfare gains rather than to welfare losses. This observation notwithstanding, if there are concerns, how should they be dealt with?

Now, were society fortunate enough to be able to turn to the frequently-invoked omniscient and omni-benevolent social planner to direct economic activity, this problem would be readily solved (along with every other known problem). In reality, society is not so blessed and difficult choices must be made about the extent and nature of the policy instruments used.

A starting point in examining these choices is some consideration of the differences between competition policy instruments on the one hand and direct economic regulation on the other. Simplifying greatly the difference between competition policy and regulation is that while competition policy tells firms what not to do, regulation involves telling them what they are to do. Competition policy sets bounds on acceptable behaviour.

In practice, the bounds competition policy sets on behaviour are likely to be very broad indeed. Regulation typically - though not inevitably - selects a much narrower range of points and directs the regulated entity to seek to attain that range. Regulation, therefore, prescribes while competition policy proscribes.

Related to this difference is a significant difference in the institutions through which these instruments are administered. Again, simplifying greatly, the task of determining whether conduct is in breach of the competition laws is almost everywhere delegated to courts, which in carrying out that task rely on standard rules of evidence and of procedure.

In contrast, the task of economic regulation is almost invariably carried out by specialist regulators, that typically have far greater powers of initiative and to secure and process information than have the courts.

These differences in institutional characteristics are, in my view, of great relevance to the allocation of problems to alternative governance instruments. There is a considerable body of relevant theory here, but time prevents me from setting it out at any length at all.

But one central insight of that theory is, however, worth noting. That core insight is that there is a fundamental trade-off between institutional capability on the one hand and vulnerability to influence activities on the other.

All this means is that the wider the range of decision-making capabilities an institution has in terms of its capacity to initiate action, the resources on which it can draw in the decision-making process, the range of outcomes it can proscribe, its scope to adjust decisions in the light of outcomes, and its ability to monitor implementation and compliance, the greater will be the principal-agent problems involved in controlling that institution's conduct.

Allocating the governance of social problems to institutions with high capabilities, therefore involve a cost which is very similar to the "information rent" familiar from the modern theory of regulation. One form this rent typically takes is the transfer of income by the regulator from less favoured to more favoured groups, usually with the objective of buttressing the regulator's own power and, hence, ability to pursue its private objectives. In the process, efficiency can be reduced rather than enhanced.

Given the cost this involves, regulation is most likely to be desirable when four conditions are met. First, there must be compelling grounds for believing that, left to their own devices, 
markets will not only fail, but will also fail to an extent that imposes material social costs. If this condition is not met, then the costs of regulation are almost certain to exceed the benefits.

The second is that there must be some ability to identify the appropriate outcome. For example, for regulation of interchange fees to be desirable, regulators must be assumed to have some ability to determine a tolerably efficient level of those fees. Meeting this condition is clearly necessary if regulation is to do better than markets on their own.

The third condition is that identifying the appropriate outcome must require ongoing monitoring and adaptation to changing economic circumstances. When this condition is met, regulatory institutions, with their standing bureaucracies and specialist expertise, are likely to be most plainly superior to courts. Alternatively, if it is sufficient to determine the matter 'once and for all' then there is less justification for relying on specialist regulators, who are more likely than courts to be vulnerable to rent-seeking and other influence activities.

Fourth and last, there must be some effective means of dealing with the pathologies to which regulation is prone, including regulation's vulnerability to rent seeking, not least by the regulatory body itself. One important form of rent seeking is time inconsistency in which the regulator expropriates, or has the scope to expropriate, the sunk costs of the regulated entity, with the risk of that expropriation then deterring regulated firms for making socially desirable investments, including the development of new products and prices.

Set against these conditions, card-based payment systems seem like rather poor candidates for regulation. First, the evidence of market failure and of its likely costs is hardly conclusive. Second, the absence of this evidence is not unrelated to the fact that formidable difficulties are involved in determining the right interchange fee and, hence, in defining a standard for assessing whether actual interchange fees are excessive.

Third, given the absence of such a standard, a regulator would have little to guide it toward sensible decision making. There is a contrast here to conventional public utility regulation, where there is some degree of consensus - at least at a theoretical level - about how prices should be set. Fourth, the lack of such a standard means that regulators would have broad discretion as there is not a well-accepted benchmark against which regulatory decisions can be judged. This broad discretion would undermine constraints against rent seeking and other abuses of the regulatory prices.

Fifth, particularly in jurisdictions where regulators are not subject to full merits review of their decisions, the resulting risk of time inconsistency could discourage investment and innovation in card-based systems.

Now, I believe that the Australian experiment with regulation of card-based systems is broadly consistent with these predictions. First, there can be no doubt that the experiment is proceeding with little guidance from economic analysis as to what objectives it should pursue or how those objectives should be solved.

In particular, the Reserve Bank of Australia's (RBA) decision to set interchange fees on the basis of what it believes to be costs incurred by issuers but attributable to merchants bears little relation, if any, to economic theory. Like the drunk who looks where the light shines, the only justification the RBA gives for setting interchange fees on this basis is that it is a standard that it is capable of implementing.

Second, given a broad discretion, the RBA seems to be focusing primarily on income transfers rather than on efficiency gains. Much as the interest group theory of regulation predicts, these transfers flow, at least in part, from a highly un-concentrated group, i.e., card holders, to a 
highly concentrated and vocal group, i.e., merchants. Absent tangible efficiency gains, these income transfers are largely arbitrary and, hence, seem offensive to good public policy.

Third, the predominance of transfers reflect the fact that there has been relatively little apparent change in behaviour, despite significant changes in effective charges for cards. Peculiarly, the RBA has not drawn from this lack of any significant quantity response the obvious conclusion which is that the relevant quasi demands cannot have been highly elastic at the initial price levels. However, if the RBA's oft-repeated premise for regulating (that initial prices were highly distorting) had been correct, then those demands should have been elastic.

The evidence to date, in other words, seems inconsistent with the underlying premise, but that inconsistency has not, in any way, affected the determination with the policy is pursued

Fourth, the Australian experience bears out one of the truly recurring conclusions economists have reached in more of a century study of regulation: that regulators, when they set out to tinker with relative prices, are driven by the unintended consequences of this tinkering to extend the scope of regulation ever further.

Thus, starting from open-system credit cards, the RBA has now extended the scope of its regulation to different forms of debit, to ATM cards, and is even looking at the bill-payment services B-Pay. Peculiarly, the only area to which it has not extended direct interchange fee regulation is the quasi-open credit card systems, which creates obvious issues of competitive neutrality.

In thus criticizing reliance on direct regulation, I am not suggesting that the competition policy alternative is a panacea. Rather, I believe there are questions that can validly be put about reliance on competition policy as a way of dealing with the possibility or with the actuality of persistent market failure. These questions go first to the substance of competition policy and, second, to the nature of its associated institution processes.

In terms of the substance, I do not believe that there is - at least as of yet - a clear presumption that stronger competition in payment systems improves outcomes, either for consumer surplus or for social welfare. This means that competition policy needs to be applied on a rule-of-reason basis, which then imposes a substantial burden on the decision-making process. And here three queries can be raised.

The first is whether an ex-post process of litigation can ensure that instances of abuse are indeed reasonably likely to be detected and remedied, thus creating a disincentive to that abuse occurring. And the costs and risks of litigation are obviously relevant in that assessment. A second question is whether courts are in a position to provide effective remedies. As I noted above, courts are not well placed to monitor and secure enforcement in instances where ongoing adaptation to changing circumstances - say, of costs or of demands - is needed.

Third, even if courts were effective in providing remedies in a specific instance, there is a valid question about how efficient particularized case-by-case decision making can be when there are multiple situations that need to be addressed. Even with precedent-based adjudication, there can be few economies of scope and scale to court decision making, although the extent to which this is so will doubtless vary from country to country.

Given these questions, I believe that if there were compelling evidence of persistent market failure and a clear standard that could guide regulators in imposing an alternative, then regulation could be superior to reliance on competition policy as means of tackling the problems. But these conditions are far from being met, at least in my view. Absent these conditions, regulation runs the risk of being highly costly in efficiency terms, while conventional competition policy remedies - such as reducing entry barriers and preventing unreasonable 
vertical restraints - if based on a proper rule of reason analysis, may move social welfare in the right direction.

I have left the standard disclaimer to the end, and that is for a reason. I - like many others in this room - am a veteran of the interchange wars, having been contacted by VISA Australia late one evening in 1998, when the competition regulator - the ACCC - was investigating its conduct. I assisted VISA throughout the process that led to the RBA enacting its regulations. It was a long and bloody process, but though I blame it for the loss of my boyish good looks, I'm not bitter.

In effect, like the Spanish Civil War, they may have won all the battles, but I still believe we had all the good songs. I believe it was Joan Robinson who said that economists are like oysters: they require irritation to produce pearls. At times, rationality may seem scarce in interchange debates, but irritation has never been lacking. And the debate has indeed produced significant pearls, not least by advancing our understanding (well evidenced in the papers at this conference) of the economics of two-sided markets.

Whether those pearls outweigh the costs is obviously another, open, question. In my opinion, the standard prescription - first, do no harm - counsels against the too-ready adoption by other jurisdictions of the Australian approach. This, of course, does not mean that other jurisdictions, following the excellent lead taken by the New York Federal Reserve, should not pay close attention to the Australian experiment (and invite me to travel to their undoubtedly very interesting and enjoyable city).

In following the course of that experiment, foreign observers can take comfort from the fact that we in Australia will bear all of that experiment's costs, all on our lonesome. While we do that, the rest of the world will be able to share in any benefits that the use of 20 million Australians as guinea pigs will doubtless provide to researchers and, particularly, economists worldwide for years to come. Is there really any doubt as to who has gotten the better side of that bargain? 